\title{
Resenha: O tronco e os ramos: Estudos de história da psicanálise
}

\section{Book Review: The trunk and the branches: Studies of psychoanalytic history}

\author{
Luciana Cavalcante Torquato ${ }^{1, * *}$ \& Victor Luiz Alves Mourão \\ ${ }^{1}$ Universidade Federal de Minas Gerais, Belo Horizonte, MG, Brasil \\ ${ }^{2}$ Universidade Estadual do Rio de Janeiro, Rio de Janeiro, RJ, Brasil
}

\section{Mezan, R. (20 I 4). O tronco e os ramos. São Paulo: Companhia das Letras.}

\begin{abstract}
A quem pode interessar uma história da psicanálise? Como é possível escrevê-la? O que define o que é ou não é psicanálise? Podemos dizer que $O$ tronco e os ramos, excepcional livro de Renato Mezan (2014), se não resolve essas indagações, ao menos clareia e ameniza todo esforço de respondê-las. Trata-se da compilação de conferências e capítulos publicados em outros espaços, frutos de uma investigação de mais de 30 anos dedicados a atividades acadêmicas e à história da psicanálise - que o filósofo de formação nos confessa ser a sua "verdadeira paixão". Tal dedicação à obra freudiana pode ser observada em seus dois livros fundamentais sobre o fundador da psicanálise: Freud, a trama dos conceitos (1982) - com caráter mais conceitual - e Freud, pensador da cultura (1985), em que mescla narrativa biográfica, contexto, elementos sociais e do campo cultural. Interessado particularmente em esclarecer os vínculos entre as variadas escolas de psicanálise e descobertas freudianas, Mezan dialoga com diversos autores da psicanálise e também historiadores, epistemólogos e teóricos da psicanálise e da psicologia.
\end{abstract}

O tronco e os ramos traz as indagações do psicanalista diante das variadas possibilidades que a disciplina freudiana assumiu desde seu surgimento (Mezan, 2014). Após "experimentar" divãs diferentes e se deparar com produções teóricas originadas de escolas distintas, todas elas notadamente reconhecidas e valoradas, o autor se questiona sobre a elasticidade teórica, clínica e conceitual da psicanálise. As respostas são encontradas na própria trajetória histórica do movimento psicanalítico. Ao acessar as narrativas históricas da fortuna crítica sobre a psicanálise, depara-se com relatos descritivos, assistemáticos, superficiais e redutores, que não abordavam com o vigor necessário a relação de Freud e seus sucessores.
Constata-se também, em grande parte do acervo, certo dogmatismo e intolerância por parte dos autores - o famoso "isso não é psicanálise". Para superar essas limitações, Mezan (2014) elabora sua própria forma de considerar essa narrativa, propondo uma "grade categorial para a história da psicanálise" (p. 41), que não pode ser relatada de forma linear, pois depende de amarrações, recuos e incursões conceituais atravessadas pelo contexto social/ cultural e pela clínica.

O livro está organizado em três partes, na primeira, Mezan (2014) apresenta seu método para construção da história da psicanálise, momento em que introduz sua tese sobre os paradigmas epistemológicos e metapsicológicos em Freud, as matrizes clínicas e seus vínculos com as escolas.

A partir do questionamento inicial sobre os motivos para tantas práticas singulares da psicanálise, Mezan (2014) investiga de que modo e por quais motivos o legado de Freud é ampliado e transformado por seus sucessores, considerando, essencialmente, o percurso dinâmico do movimento iniciado por Freud, os bastidores institucionais e atores influentes que permitiram à psicanálise vingar e se difundir. Nesse percurso, descobre que as perguntas que esses personagens dirigiam à Freud não eram equivalentes, pois se originavam de contextos e práticas diferentes.

O autor (Mezan, 2014) leva adiante a tese de que as correntes que se derivaram de Freud teriam trilhado percursos variados, porque teriam, em sua prática, se deparado com problemas distintos, levando-as a recorrerem a passagens ou momentos diversos na obra freudiana. Tais problemas, que podem ser entendidos como as modalidades psicopatológicas que se apresentavam na práxis analítica, fornecem elementos para o que Mezan traduz sob a insígnia de "matriz clínica", modalidade própria de organização

** E-mail: lucianatorquato@yahoo.com.br

- Submetido: 29/07/2015; Aceito: 02/12/2016. 
psicopatológica, com uma estrutura determinada e singular, com conflitos e defesa característicos.

Para o autor (Mezan, 2014), a matriz clínica freudiana, por excelência, teria sido a histeria - ainda que as demais (psicose, neurose obsessiva e melancolia) já ocupassem as preocupações e escrutínio de Freud. Cada uma das correntes pós-freudianas teria focado em uma matriz clínica específica, ramificando os usos e teorizações sobre a mesma, diante das especificidades de seu tempo/cenário. No entanto, adverte-nos Mezan que nem todas essas correntes podem ser compreendidas como escolas. Nesse momento, o autor aponta o critério necessário para que se alcance a alcunha de escola de psicanálise, a saber, o modo original e coerente com que cada corrente formula a respeito daquilo que ele nomeia como as "quatro dimensões epistemológicas" de Freud: (a) uma teoria geral da psique (teoria metapsicológica); (b) uma teoria sobre sua gênese e desenvolvimento (teoria do desenvolvimento); (c) sobre seu funcionamento normal e patológico (teoria psicopatológica); (d) e, por fim, uma teoria sobre as modalidades de intervenção na psique (teoria do processo terapêutico).

Na segunda parte do texto, Mezan (2014) elege, como objeto, o próprio Sigmund Freud, percorrendo três temas nessa seção. $\mathrm{O}$ primeiro, dedica-se às circunstâncias da ocasião de realização do filme "Freud, além da alma", incluindo, aí, a querela relacionada à encomenda do roteiro original, feita por John Houston a Sartre. O encadeamento dessa história serve para exemplificar o argumento que atravessa todo o livro, em que o autor alerta para o fato de que o texto de Freud não é a via exclusiva para compreender a psicanálise, ou seja, é preciso considerar aspectos biográficos, textuais e contextuais, sendo perigoso "reduzir a psicanálise a Freud e Freud ao seu texto" (Mezan, 2014, p. 359).

Critica, portanto, aqueles a quem nomeia de "freudólogos", por tomarem a psicanálise como simples emanação da pessoa de seu criador, reduzindo a disciplina ao inconsciente de Freud (Mezan, 2014). Ainda nessa seção, Mezan (2014) nos presenteia com uma rica análise do caso Dora, no contexto do primeiro modelo metapsicológico, buscando apreender as relações de Freud com o caso e com a escrita e tardia publicação do mesmo, concluindo - junto com Peter Gay (2012) - que o fracasso terapêutico de tal experiência teria sido a fonte para descobertas muito importantes para a psicanálise.

Ainda pensando na importância e fecundidade do ano de 1905, empreende uma análise do texto A piada e sua relação com o inconsciente (1905), pensando a ambivalência de Freud em relação ao Witz e ao primeiro sistema de psicanálise ali contido (Mezan, 2014). Ou seja, essa parte do livro estrutura-se como uma aplicação do que foi teorizado e armado metodologicamente na seção anterior: é como se Mezan (2014) nos ensinasse como escrever uma história da psicanálise para, em seguida, narrar a sua versão. Seguindo essa trilha, exibe, ainda, um estudo sobre a recepção da psicanálise no Brasil, a partir, como nos indica o autor, de duas vias principais de recepção das ideias freudianas: a vanguarda artística modernista e a psiquiatria local.

A terceira e última seção do livro aborda problemas contemporâneos da disciplina psicanalítica, relacionados à cientificidade da psicanálise e às pesquisas recentes que atualizam velhas preocupações de Freud sobre o estatuto de sua disciplina. Mezan (2014) busca pensar as fronteiras (geográfica, teórico-clínica, epistemológica, sócio-cultural) da psicanálise, levantando a necessidade de diálogo da disciplina com demais modalidades de produção humana - as ciências, teoria crítica, tradições e costumes. Intenta, ainda, pensar em como a pesquisa em psicanálise tem sido pensada na contemporaneidade e no seu enquadramento enquanto ciência humana - posto que, para o autor, seu objeto, método e perfil epistemológico se aproximam dessa ciência.

Percorrer os estudos de Mezan (2014) sobre a história da psicanálise revela questões (teóricas, metodológicas, conceituais) impostas por sua "dispersão" (geográfica, institucional e doutrinária), ou seja, transformações que a psicanálise sofre ao ser transplantada para outras culturas e contextos. Ao nos alertar para tal historicidade, o autor nos revela o fato de que as teorias que sucederam as propostas de Freud são frutos de contextos, rupturas e transformações que fazem parte de um longo processo de construção.

Em diferentes culturas (formas de agir, sentir, pensar), a psicanálise sofrerá questionamentos inéditos (no plano teórico), sendo objeto de expectativas diferentes quanto à sua eficácia (plano da clínica). O autor (Mezan, 2014) retorna ao texto freudiano compreendendo, ali, os seus pontos de tensão, recuos e avanços, apreendendo como esses movimentos provocavam distensões em seu corpo teórico, fazendo surgir diferentes escolas. Os aspectos políticos da difusão também são contemplados em sua leitura, revelando as linhas de tensão na obra de Freud, que nos fornecem importantes chaves para compreensão das fraturas entre os pós-freudianos.

Longe de estarmos assistindo ao fim ou à derrocada da psicanálise, Mezan (2014) aposta que, ao atingir seu segundo século de existência, a disciplina psicanalítica demonstra sinais de vitalidade, uma vez que sua prática e o campo social continuam apontando questões, convocando, portanto, a teoria a aperfeiçoar suas ferramentas conceituais. Dessa forma, o livro é de grande relevância para aqueles que buscam conhecer as modalidades das formas de vida no seio da contemporaneidade: para historiadores da ciência e do pensamento moderno; psicanalistas e psicólogos preocupados com as raízes históricas da sua disciplina e, ainda, para aqueles psicanalistas que almejam se aprofundar na teoria freudiana para além dos "originais".

Uma pertinente justificativa para um retorno à trajetória dessa disciplina, fundada na finissecular Viena de Freud, é a possibilidade que a mesma nos fornece para a compreensão de questões clínicas e sociais atuais, como bem argumenta 
o filósofo-psicanalista. Ainda que o contexto e panorama tenham mudado radicalmente desde Freud, escrever uma história de sua disciplina acaba sendo uma forma de inová-la e oxigenar suas teses, interrogando as origens das preocupações do campo e revelando os problemas que a psicanálise sempre buscou responder.

Dessa forma, apreendendo sua história enquanto ramo de conhecimento sobre o homem, percebemos a trama das sociedades, seus modos de gozo, de padecimento, de produção e trabalho. Ao citar o poeta Luís de Camões em sua epígrafe, Mezan (2014) nos presenteia com versos que nos contam o enredo de um amor tão longo para tão curta vida. Há existências, no entanto, tão frutíferas que se desenrolam para além de sua temporalidade contida no tempo de uma vida. Esse parece ser o legado de Freud, que estende vigorosamente seus ramos para além do tronco. Esse parece ser o trabalho de Mezan, que, partindo dessas ramificações, arvora-se em frutíferas amarrações.

\section{Referências}

Gay, P. (2012). Freud: uma vida para nosso tempo. São Paulo: Companhia das Letras.

Mezan, R. (1982). Freud: a trama dos conceitos. São Paulo: Perspectiva.

Mezan, R. (2006). Freud, pensador da cultura. São Paulo: Companhia das Letras. 